OPEN ACCESS

Edited by:

Akio Adachi,

Tokushima University Graduate

School, Japan

Reviewed by:

Hirotaka Ode,

National Hospital Organization Nagoya

Medical Center, Japan

Frederick Joseph Fuller,

North Carolina State University, USA

Reena Ghildyal,

University of Canberra, Australia

*Correspondence: Hui Yee Chee

cheehy@upm.edu.my

Specialty section:

This article was submitted to Virology,

a section of the journal Frontiers in Microbiology

Received: 29 January 2016 Accepted: 04 April 2016 Published: 29 April 2016

Citation:

Khaw YS, Chan YF, Jafar FL, Othman N and Chee HY (2016) Comparative Genetic Analyses of

Human Rhinovirus C (HRV-C) Complete Genome from Malaysia.

Front. Microbiol. 7:543

doi: 10.3389/fmich.2016.00543

\section{Comparative Genetic Analyses of Human Rhinovirus C (HRV-C) Complete Genome from Malaysia}

\author{
Yam Sim Khaw ${ }^{1}$, Yoke Fun Chan ${ }^{2}$, Faizatul Lela Jafar ${ }^{2}$, Norlijah Othman ${ }^{3}$ and \\ Hui Yee Chee ${ }^{1 *}$
}

${ }^{1}$ Department of Medical Microbiology and Parasitology, Faculty of Medicine and Health Sciences, Universiti Putra Malaysia, Serdang, Malaysia, ${ }^{2}$ Department of Medical Microbiology, Faculty of Medicine, University of Malaya, Kuala Lumpur, Malaysia, ${ }^{3}$ Department of Paediatrics, Faculty of Medicine and Health Sciences, Universiti Putra Malaysia, Serdang, Malaysia

Human rhinovirus-C (HRV-C) has been implicated in more severe illnesses than HRV-A and HRV-B, however, the limited number of HRV-C complete genomes (complete $5^{\prime}$ and $3^{\prime}$ non-coding region and open reading frame sequences) has hindered the in-depth genetic study of this virus. This study aimed to sequence seven complete HRV-C genomes from Malaysia and compare their genetic characteristics with the 18 published HRV-Cs. Seven Malaysian HRV-C complete genomes were obtained with newly redesigned primers. The seven genomes were classified as HRV-C6, C12, C22, C23, C26, C42, and pat16 based on the VP4NP2 and VP1 pairwise distance threshold classification. Five of the seven Malaysian isolates, namely, 3430-MY-10/C22, 8713-MY-10/C23, 8097-MY-11/C26, 1570-MY-10/C42, and 7383-MY-10/pat16 are the first newly sequenced complete HRV-C genomes. All seven Malaysian isolates genomes displayed nucleotide similarity of $63-81 \%$ among themselves and 63-96\% with other HRV-Cs. Malaysian HRV-Cs had similar putative immunogenic sites, putative receptor utilization and potential antiviral sites as other HRV-Cs. The genomic features of Malaysian isolates were similar to those of other HRV-Cs. Negative selections were frequently detected in HRV-Cs complete coding sequences indicating that these sequences were under functional constraint. The present study showed that HRV-Cs from Malaysia have diverse genetic sequences but share conserved genomic features with other HRV-Cs. This genetic information could provide further aid in the understanding of HRV-C infection.

Keywords: Malaysia, complete genome, HRV-C, genomic feature, phylogenetic, negative selection

\section{INTRODUCTION}

Human rhinovirus (HRV) has been recognized as one of the respiratory viruses associated with common cold in humans since the late 1950s. HRV infection is a significant burden that is frequently associated with morbidity and mortality among hospitalized pediatric patients not only in Malaysia, but also worldwide (Etemadi et al., 2013). HRV has more than 100 serotypes, which have been clustered into three groups: HRV-A, B, and C (McIntyre et al., 2013). To date, HRV-A consists of 80 serotypes, HRV-B consists of 32 types, and HRV-C consists of 55 types (Picornaviridae Study Group, 2014).

HRV-C, which was discovered in 2006, is a new species of HRV and has led to the reemergence of research interest in HRV (Lamson et al., 2006; Lau et al., 2007). The unique characteristics of 
HRV-C that distinguish it from HRV-A and HRV-B include the lack of usage of both major and minor receptors for host binding (Bochkov et al., 2011), potential resistance to pleconaril, a higher GC content, and a series of nucleotide deletions in the VP1 region, which yields a shorter complete genome (Lau et al., 2007).

A clearer picture of biological properties of HRV-A and HRV-B has been revealed through several studies that utilized a large number of HRV-A $(n>80)$ and HRV-B $(n>30)$ complete genome sequences in the Genbank (Palmenberg et al., 2009, 2010). Currently, there are only 18 HRV-C complete genomes (with complete $5^{\prime}$ non-coding region (NCR), $3^{\prime}$ NCR and open reading frame (ORF) sequences) available. This has greatly hampered the further study of this virus. Only partial and complete HRV-C VP1 and VP4/VP2 sequences have been largely published in the Genbank, hence, no in-depth analysis of the genomic features is possible.

Many studies have reported higher occurrence of HRV-C than HRV-A and HRV-B in severe respiratory diseases (McErlean et al., 2007; Miller et al., 2009). In addition, the association of specific HRV sequences with clinical severity is not well understood. To date, most of the published studies focused on the HRV-C capsid regions. Thus, a comparative sequence analysis using HRV-C complete genomes is an effective approach to gain more insight into this virus. In the present study, seven HRV-C complete genomes from children with respiratory tract infections in Malaysia were sequenced and comparative analyses of Malaysian isolates with other HRV-Cs were performed. This is the first report on the complete genome sequencing and comparative analyses of HRV-C from Malaysia. Seven HRV-C complete genome sequences were successfully amplified in the present study and comparative genetic analyses demonstrated that all HRV-Cs, as well as Malaysian isolates, share the same genomic features even though their nucleotide sequences are highly variable. This genetic information is useful for future studies of HRV-C pathogenesis and undoubtedly will make a significant contribution in the understanding of rhinovirus genomics.

\section{MATERIALS AND METHODS}

\section{Patient Recruitment and Sample Collection}

Seven nasopharyngeal aspirate (NPA) samples were collected from children with respiratory tract infection at University Malaya Medical Center (UMMC) in Malaysia between October 2010 and May 2011 (Medical Ethic Approval no. 788.3) (Chan et al., 2012). These samples were previously confirmed as HRV-C based on the sequence of the VP4/VP2 region (Chan et al., 2012). RNA was extracted using QIAamp Viral RNA Mini Kit (Qiagen, Germany) according to the manufacturer's instructions.

\section{Redesigning Primers}

Three HRV-C complete genomes (accession number: EF582385, EF582386, and EF582387) were aligned by using ClustalW implemented in the MEGA6 program package (Tamura et al., 2013). Primers were modified and redesigned based on the primers used by Lau et al. (2007), and the redesigned primers were based on conserved regions to generate amplicon of less than $1 \mathrm{~kb}$ (Supplementary Table 1).

\section{Complete Genome Sequencing}

cDNA was synthesized using the SuperScript III kit (Invitrogen, USA) according to the manufacturer's instructions with minor modifications. A combined random priming and oligo (dT) priming strategy was utilized to produce cDNA. The reaction mixture contained $2.75 \mu \mathrm{L}$ of RNA, a mixture of $5 \mu \mathrm{M}$ random hexamer (Thermo Scientific, USA) and $0.5 \mu \mathrm{M}$ oligo- $\mathrm{dT}_{18}$ (Thermo Scientific, USA) (a ratio of 10:1), $0.5 \mathrm{mM}$ dNTP, 1X first strand buffer ( $250 \mathrm{mM}$ Tris-HCl pH 8.3, $375 \mathrm{mM} \mathrm{KCl}, 15 \mathrm{mM}$ $\mathrm{MgCl}_{2}$ ), $5 \mathrm{mM}$ DTT, $10 \mathrm{U}$ RNaseOUT (Invitrogen, USA), $50 \mathrm{U}$ SuperScript III reverse transcriptase, and nuclease-free water to a final volume of $5 \mathrm{uL}$. The mixture was incubated at $25^{\circ} \mathrm{C}$ for $10 \mathrm{~min}$, followed by incubation at $55^{\circ} \mathrm{C}$ for $60 \mathrm{~min}$, and a final incubation at $70^{\circ} \mathrm{C}$ for $15 \mathrm{~min}$.

PCR amplification was performed with $1 \mu \mathrm{L}$ cDNA, 1X Colorless GoTaq Flexi Buffer, $3 \mathrm{mM} \mathrm{MgCl} 2,0.2 \mathrm{mM}$ dNTP (Fermentas, USA), $1.0 \mu \mathrm{M}$ of each forward and reverse primer, and 1 U GoTaq Flexi DNA Polymerase (Promega, USA) for a final volume of $25 \mu \mathrm{L}$. This reaction was subjected to thermal cycling at $95^{\circ} \mathrm{C}$ for $5 \mathrm{~min}$, followed by 35 cycles each consisting of denaturation at $95^{\circ} \mathrm{C}$ for $1 \mathrm{~min}$, annealing for $1 \mathrm{~min}$ (annealing temperature varies with different primers in Supplementary Table 1), and extension at $72^{\circ} \mathrm{C}$ for $1 \mathrm{~min}$ and a final extension at $72^{\circ} \mathrm{C}$ for 5 min using MyCycler Thermal Cycler (BioRad, USA). The $5^{\prime}$ and $3^{\prime}$ NCRs of the viral genome were amplified using the $5^{\prime}$ rapid amplification of cDNA ends (RACE) system and $3^{\prime}$ RACE system (Invitrogen, USA), respectively, according to manufacturer's protocol.

The PCR products were gel-purified using the gel/PCR DNA fragments extraction kit (Geneaid, Taiwan). These products were bi-directionally sequenced with both forward and reverse primers by First Base Laboratories Sdn Bhd (Selangor, Malaysia). NCRs and the insufficient concentration of purified PCR products were cloned into the $\mathrm{yT} \& \mathrm{~A}$ vector (Yeastern, Taiwan) and transformed into Top 10F' Escherichia coli following the manufacturer's protocol. Then, plasmids from three positive bacteria clones were extracted and purified using the HighSpeed Plasmid Mini Kit (Geneaid, Taiwan). These positive plasmids were sent to First Base Laboratories Sdn Bhd (Selangor, Malaysia) for sequencing using ABI3770 sequencer (Applied Biosystems, USA).

\section{Genome Alignment}

The sequences were edited and assembled with the use of BioEdit version 7.1.11 software (Hall, 1999). Eighteen HRV-C complete genome references (with complete $5^{\prime} \mathrm{NCR}, 3^{\prime} \mathrm{NCR}$ and ORF) up until January 2016 were retrieved from the GenBank. These HRV-Cs were used in comparative analysis and are referred to as "other HRV-Cs." Alignment of the seven HRV-C gene sequences completed in this study and the other HRV-Cs complete genomes was performed by using ClustalW implemented in the MEGA6 program package (Tamura et al., 2013).

\section{Phylogenetic Analysis}

JmodelTest 2.1.1 (Darriba et al., 2012) was used to determine the best-fit nucleotide substitution model. The maximum likelihood phylogenetic tree was constructed using General Time Reversible (GTR) as the best substitution model with gamma distributed 
and invariant sites. To construct the phylogenetic trees, bootstrap values calculated from 1000 trees were implemented in the MEGA6 program package (Tamura et al., 2013). The bootstrap values of 70 or higher were considered as significant clustering.

\section{Pairwise Similarity}

Pairwise similarity among the nucleotide of HRV-Cs complete genomes and complete coding sequences, and complete coding deduced amino acid sequences were calculated with the use of the GeneDoc 2.7.000 software (Nicholas et al., 1997).

\section{Sequence Analyses}

The nucleotide sequences of Malaysian isolates and other HRVCs were translated into deduced amino acid sequences using MEGA6 program package (Tamura et al., 2013). The deduced amino acid and NCR sequences of Malaysian isolates and other HRV-Cs were aligned with reference sequences: HRV16 (accession number: L24917, HRV-A), HRV-2 (accession number: X02316, HRV-A), HRV-1 (accession number: FJ445111, HRV-A), HRV-1B (accession number: D00239, HRV-A), HRV3 (accession number: EF173422, HRV-B), HRV-14 (accession number: NC_001490, HRV-B), HRV-70 (accession number: DQ473489, HRV-B), or coxsackievirus B3 (accession number: M33854, CV-B3) using ClustalW implemented in the MEGA6 program package (Tamura et al., 2013) to determine the functional motifs.

\section{Selective Pressure Analysis}

The synonymous $(\mathrm{dS})$ and non-synonymous $(\mathrm{dN})$ changes at every codon of all the HRV-C complete coding sequences, including seven Malaysian isolates $(n=25)$, were estimated using three different selective pressure analyses implemented in DataMonkey (http://www.datamonkey.org) (Pond and Frost, 2005). The analyses were single likelihood ancestor counting (SLAC), fixed effects likelihood (FEL), and internal fixed effects likelihood (IFEL). These methods were conducted using the GTR model of nucleotide substitution and neighbor-joining method to determine the rate for $\mathrm{dN}$ and $\mathrm{dS}$. In addition, the estimation of positive and negative selections was determined using $p$-value of 0.1 . The synonymous rate exceeding the non-synonymous rate was considered as negative selection $(\mathrm{dS}>\mathrm{dN})$, while the positive selection was defined as when the non-synonymous rate exceeds the synonymous rate $(\mathrm{dN}>\mathrm{dS})$. Neutral selection was defined when the non-synonymous rate equals to the synonymous rate $(\mathrm{dN}=\mathrm{dS})$.

\section{Nucleotide Sequence Accession Numbers}

The complete genomes of seven Malaysian isolates were deposited in the GenBank under the accession numbers KF734978, KJ675505, KJ675506, KJ675507, KP890662, KP890663, and KP890664.

\section{RESULTS}

\section{Malaysian Isolates Showed Highly Diverse Nucleotide Sequences}

Complete genomes of seven HRV-Cs (1515-MY-10, 1570-MY10, 3430-MY-10, 3805-MY-10, 7383-MY-10, 8097-MY-11, and
8713-MY-10) were successfully sequenced in this study. Similar to other HRV-Cs, the nucleotide length of the Malaysian isolates complete genomes ranged from 7087 to $7127 \mathrm{bp}$, with an ORF that encoded for a polyprotein of 2139-2155 amino acids. Complete $5^{\prime}$ NCR and $3^{\prime}$ NCR lengths were 611-640 bp and $41-52 \mathrm{bp}$, respectively. The GC content of all the isolates was 42.3-43.8\% (Supplementary Table 2).

Malaysian isolates complete genomes and complete coding sequences showed nucleotide similarity of $63-81 \%$ among themselves and 63-96\% with other HRV-Cs (Table 1). In addition, Malaysian isolates demonstrated complete coding deduced amino acids similarity of $66-91 \%$ among themselves and $65-99 \%$ with other HRV-Cs. These results show that immense differences in both nucleotide and deduced amino acids sequences were observed among Malaysian isolates. Low nucleotide pairwise sequence similarity with different types of the other HRV-Cs suggests that Malaysian HRV-Cs are genetically diverse.

\section{Phylogenetic Analysis Based on All the Available Complete Genomes Showed a Different Clustering Pattern Compared to VP1 Gene}

Phylogenetic analysis of HRV-C complete genomes showed no clear geographical or temporal segregation of the Malaysian isolates and other HRV-Cs (Figure 1). The analysis revealed that 1515-MY-10 was closely related to 026 from Hong Kong, which has been classified as HRV-C6, and the nucleotide similarity was as high as $96 \%$ for the complete genome (Table 1). In addition, isolate 7383-MY-10 was also clustered with a group of C6 from Hong Kong and China and one HRV-C3 (QPM) from Australia. Isolate 3430-MY-10 showed a similar grouping pattern with 7383-MY-10, which this isolate grouped with an additional closer strain, NY-074 (C7) from USA compared to 7383-MY-10, while 8097-MY-11 grouped with C51 lineage from China and USA. Besides, isolate 3805-MY-10, which was closely clustered with LZY101 (C12) from China, also showed 92\% of nucleotide similarity in the complete genome (Table 1). Isolate 1570-MY10 was grouped together with 3805-MY-10 and LZY101 (C12), whereas 8713-MY-10 demonstrated a closer relationship with 2536 (C41) from the USA (Figure 1). Despite the obvious clustering pattern, the nucleotide similarities between 7383-MY10, 3430-MY-10, 8097-MY-11, 1570-MY-10, 8713-MY-10 and their respective HRV-C in the clustering were only $74-81 \%$ (Table 1).

To perform the phylogenetic analysis based on the VP1 gene, a phylogenetic tree was built using the HRV-C complete VP1 gene from the available sequences in the Genbank. While there were many VP1 sequences in the Genbank for a single HRV-C type, only one VP1 sequence was chosen to represent each HRV-C type. Similar to the tree drawn with complete genome, 1515MY-10 and 3805-MY-10 were still grouped with C6 and C12, respectively (Figures 1, 2); however, isolate 1570-MY-10 was later grouped with C42, 3430-MY-10 with C22, 7383-MY-10 with C1, 8097-MY-11 with C26, and 8713-MY-10 with C23 (Figure 2). The observed differences were due to the absence of $\mathrm{C} 1, \mathrm{C} 22$, C23, C26 and C42 complete genomes in Genbank. 


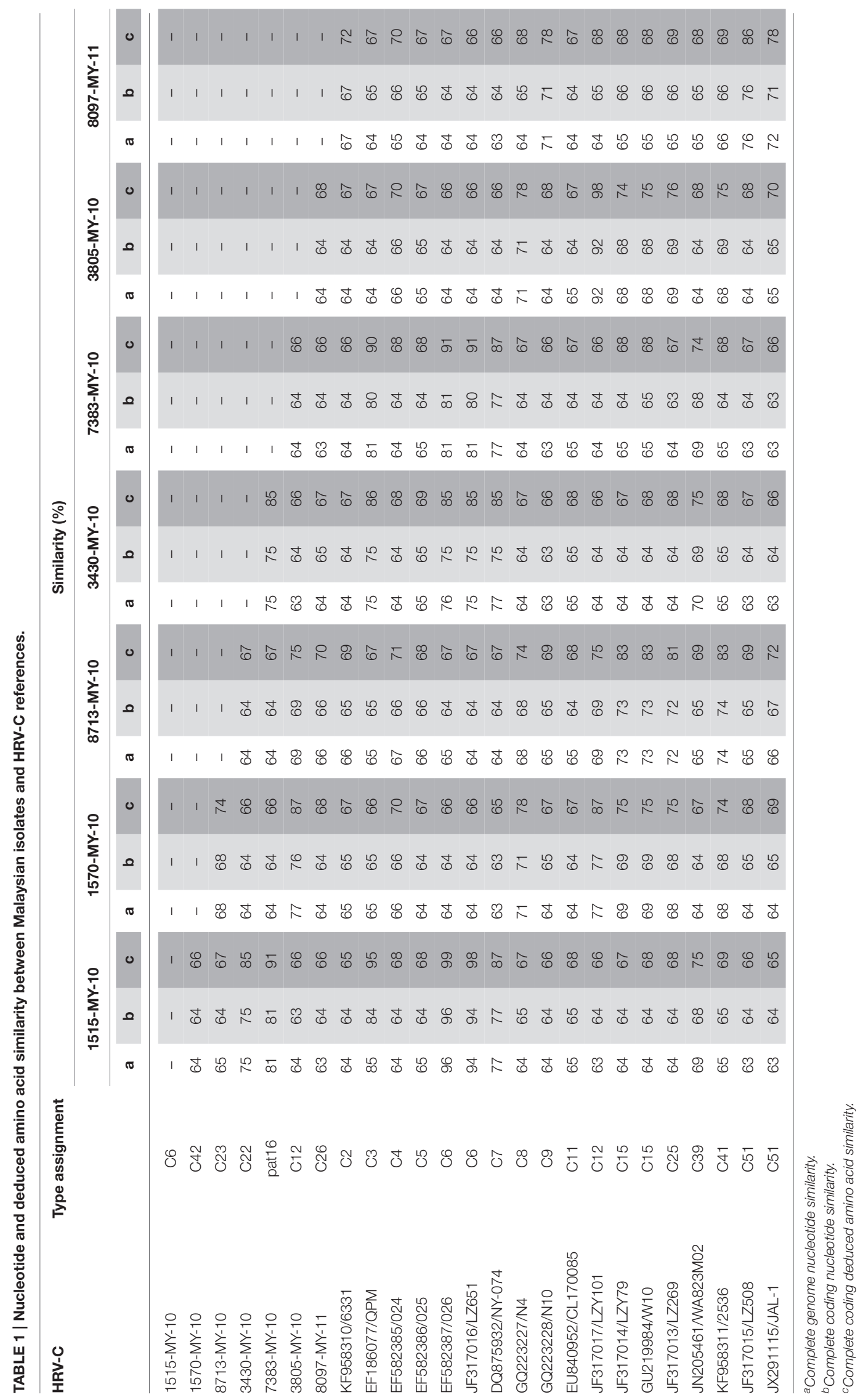




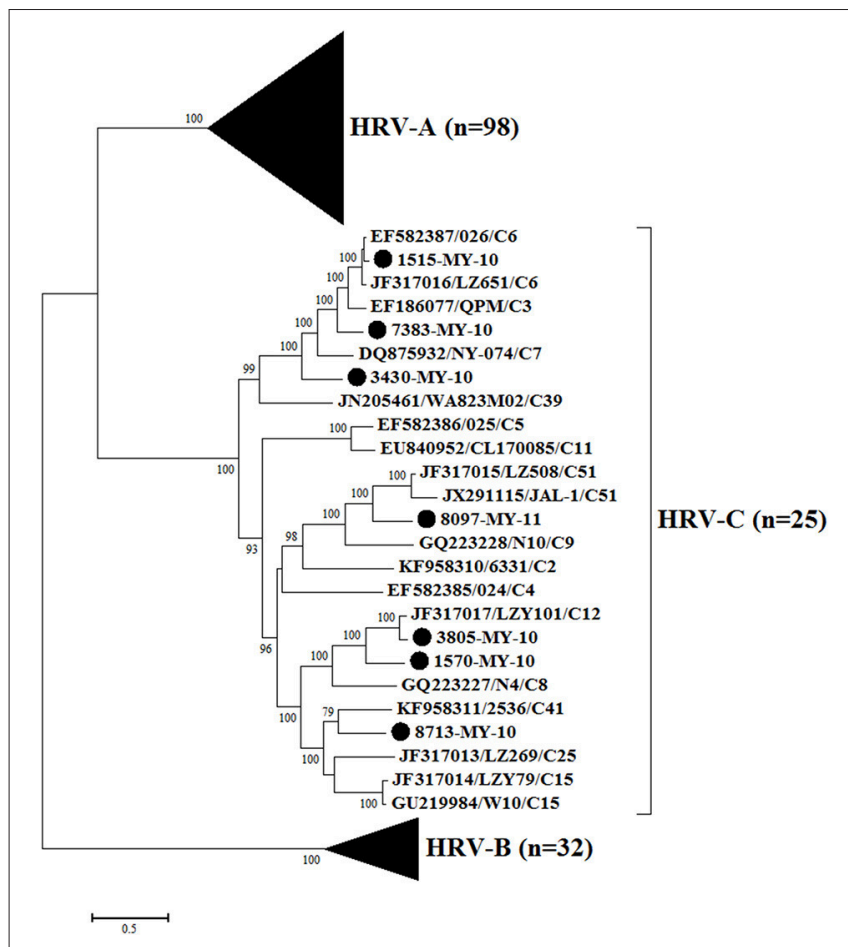

FIGURE 1 | Phylogenetic analysis of complete genome sequences of HRV-A, B, and C and seven Malaysian isolates used in this study. The Malaysian isolates were denoted as (•). Tree was constructed by using maximum likelihood method and General Time Reversible as substitution model with gamma distributed with invariant sites rate, with 1000 bootstrap replicates implemented in the program MEGA version 6. Black triangles represent HRV-A and HRV-B isolates, respectively. Only bootstrap values with higher than $70 \%$ were shown.

\section{Pairwise Similarity Analysis Revealed Five New HRV-C Complete Genomes}

Majority of the Malaysian isolates were consistent with pairwise distance threshold classification (Simmonds et al., 2010). They displayed more than $90 \%$ similarity with their respective HRV-C reference in both VP4/VP2 and VP1 nucleotide sequences, except for 7383-MY-10 (Supplementary Table 3). In a previous phylogenetic analysis, 7383-MY-10 demonstrated a closer relationship with pat16 in VP4/VP2 sequence (Chan et al., 2012). In this analysis, isolate 7383-MY-10 showed a highly similar result to pat16 with $93 \%$ in VP4/VP2 sequence, but did not show more than $90 \%$ similarity with any available HRV-C VP1 sequences at nucleotide level. The most similar HRV-C VP1 nucleotide sequence available in Genbank to 7383MY-10 was HRV-C1 (NAT001, accession number: EF077279), for which the similarity was only $83 \%$. Pat16 is one of the provisional HRV-Cs awaiting HRV-C type classification due to the absence of VP1 sequence (Picornaviridae Study Group, 2014).

Taken together the phylogeny and pairwise similarity analyses, the seven Malaysian isolates in this study, 1515-MY-10, 3805-MY-10, 3430-MY-10, 8713-MY-10, 8097-MY-11, 1570MY-10, and 7383-MY-10 were classified as HRV-C6, C12,

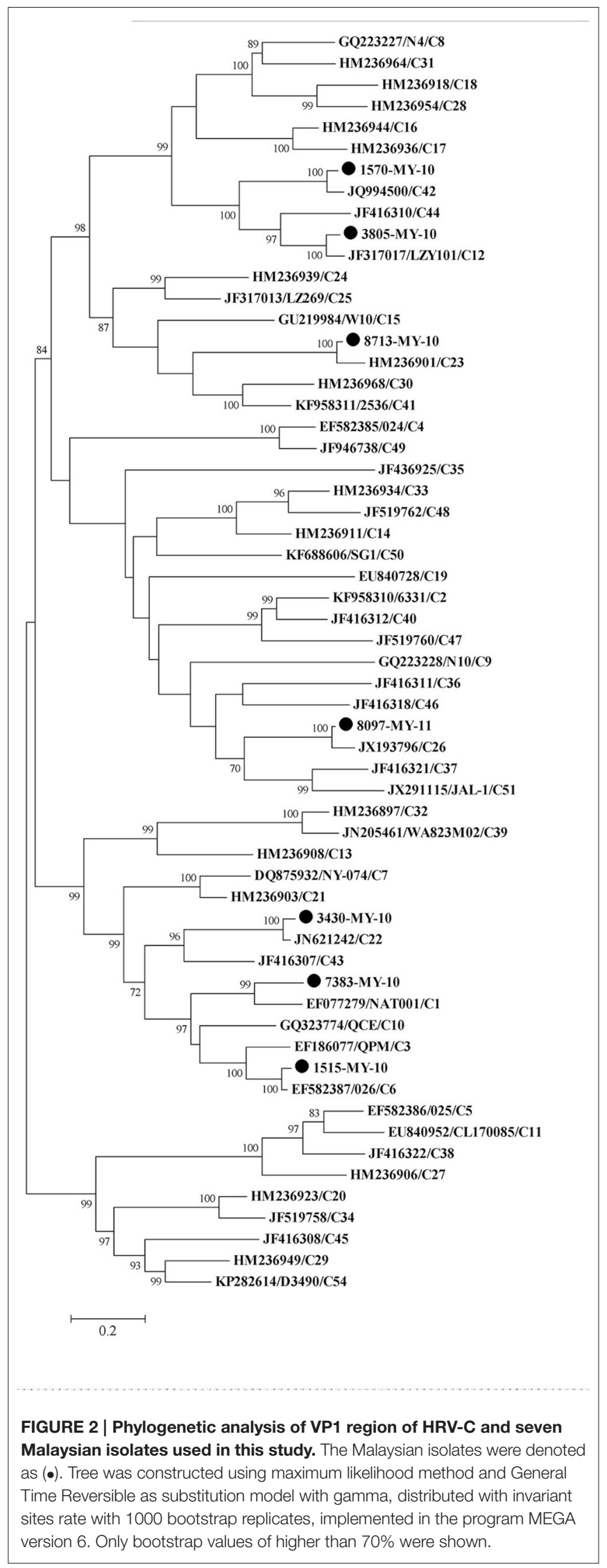


C22, C23, C26, C42, and pat16, respectively. Since only two Malaysian isolates, 1515-MY-10 and 3805-MY-10 showed high complete genome sequence similarity with their respective HRV-C references, 026/C6 (accession number: EF582387) and LZY101/C12 (accession number: JF317017), therefore, the remaining five $\mathrm{HRV}-\mathrm{C}$ isolates from Malaysia are likely to represent newly sequenced HRV-C complete genomes.

\section{Malaysian Isolates Shared Similar Functional and Genetic Features with Other HRV-Cs}

As HRV-C is not readily propagated in typical culture system, the immunogenic sites of $\mathrm{HRV}-\mathrm{C}$ were predicted using comparative sequence analysis of HRV-A (HRV-2, accession number: X02316) (Appleyard et al., 1990) and HRV-B (HRV-14, accession number: K02121) (Rossmann et al., 1985). Similar to other HRV-Cs, the Malaysian isolates were shorter in length as compared to HRV-A and HRV-B due to several deletions in the VP1 loops (Table 2). These deleted regions are $\mathrm{BC}, \mathrm{DE}$, and $\mathrm{HI}$ loops. $\mathrm{BC}$ and $\mathrm{DE}$ loops are known as immunogenicity determinants in HRV-A and HRV$\mathrm{B}$, while $\mathrm{HI}$ loop is not related to immunogenic site; thus, HI loop is excluded from Table 2. The locations of immunogenic sites of HRV-A are different from HRV-B, except for position 85 . Five (positions 85, 91, 95, 138, and 139) of six HRV-B immunogenic sites were deleted in HRV-Cs, whereas only two (positions 85 and 86) of nine HRV-A immunogenic sites were deleted in the Malaysian isolates and other HRV-Cs VP1 protein.

Malaysian isolates shared six out of seven and three out of nine conserved deduced amino acids with HRV-A and HRV$\mathrm{B}$ major receptor binding sites, respectively (Table 3 ). The only dissimilar deduced amino acid of Malaysian isolates with HRVA major receptor binding sites was located at position 180 in VP3 region (according to HRV-A). Malaysian isolates displayed several different deduced amino acids such as alanine (A), lysine $(\mathrm{K})$, or serine $(\mathrm{S})$ at position 180 in VP3 region, whereas
HRV-A has proline (P) at that position. The other HRV-Cs shared five out of seven deduced amino acids with HRV-A major receptor binding sites (Lau et al., 2007). Intriguingly, an additional deduced amino acid in the HRV-A major receptor binding site, threonine (T), was displayed by isolate $8713-\mathrm{MY}$ 10/C23 in the position 179 of VP3 region (according to HRV-A). On the other hand, $\mathrm{Lys}_{224}(\mathrm{~K})$ amino acid in VP1 region was not seen in Malaysian isolates. The absence of this amino acid was due to the deletion of HI loop in the VP1 protein (data not shown).

Of the 25 amino acids, 15 and 14 amino acids corresponding to the pleconaril antiviral binding sites of HRV-A and HRV$B$, respectively, were found in Malaysian isolates and other HRV-Cs (Table 4; Ledford et al., 2004). Also, these HRVCs demonstrated seven antiviral binding sites that were not analogous to HRV-A or HRV-B. These antiviral binding sites were located at positions 93, 113, 127, 166, 169, 221, and 243 (according to HRV-C024 accession number: EF582385). The putative antiviral binding sites of the Malaysian isolates and other HRV-Cs were superimposable onto the binding sites of HRV-A and HRV-B based on the same crucial $\mathrm{C}_{\alpha}$ backbone present in each HRV group (Basta et al., 2014a). A minority group of HRV-Bs displaying $\mathrm{Phe}_{152}(\mathrm{~F})$ and $\mathrm{Leu}_{191}$ (L) in the VP1 sequence were found to be associated with resistance to pleconaril (Ledford et al., 2004). Phe 152 of HRV-B is equivalent to HRV-C Phe 129 . Four Malaysian isolates (1515-MY-10/C6, 3430MY-10/C22, 8713-MY-10/C23, and 7383-MY-10/pat16) and the majority of other HRV-Cs displayed only $\mathrm{Phe}_{129}$ amino acid but not Leu 191 in the VP1 sequence (data not shown).

Many conserved motifs can be observed in the HRV genome. The genomic features of the Malaysian isolates and other HRV-Cs are summarized in Table 5. In the VP4 region, a conserved myristoylation motif, GAQVS motif, is essential for capsid protein assembly (Paul et al., 1987). This motif constitutes MGAQVS motif that is responsible for translation site of HRV polyprotein (Arden et al., 2010). Both of the

TABLE 2 | Summary of predicted HRV-C deduced amino acids and their positions in the VP1 region based on HRV-A (Appleyard et al., 1990) and -B immunogenic sites (Rossmann et al., 1985).

\begin{tabular}{|c|c|c|c|c|c|c|c|c|c|c|c|c|c|c|}
\hline \multirow[t]{2}{*}{ HRV } & \multicolumn{14}{|c|}{ Position $\#$} \\
\hline & 83 & $85^{a}$ & $86^{a}$ & $91^{b}$ & $92^{\mathrm{a}}$ & $95^{b}$ & 138 & 139 & 264 & 267 & 268 & 269 & 276 & 278 \\
\hline HRV-A & - & $\mathrm{T}$ & $\mathrm{L}$ & - & $E$ & - & - & - & K & $\mathrm{D}$ & $\mathrm{R}$ & $S$ & $\mathrm{~T}$ & $\mathrm{P}$ \\
\hline \multirow[t]{3}{*}{ HRV-B } & Q & K & - & $\mathrm{D}$ & - & $E$ & $\mathrm{D}$ & $S$ & - & - & - & - & - & - \\
\hline & \multicolumn{14}{|c|}{ Position* } \\
\hline & 83 & NPa & NPa & $N P^{b}$ & $84^{a}$ & $N P^{b}$ & NP & NP & 248 & 258 & 259 & 260 & 267 & 269 \\
\hline Other HRV-Cs & $\mathrm{A} / \mathrm{D} / \mathrm{E} / \mathrm{K} / \mathrm{N} / \mathrm{Q} / \mathrm{R} / \mathrm{S} / \mathrm{T}$ & $\varnothing$ & $\varnothing$ & $\varnothing$ & $\mathrm{D} / \mathrm{E} / \mathrm{N} / \mathrm{Q} / \mathrm{R} / \mathrm{S}$ & $\varnothing$ & $\varnothing$ & $\varnothing$ & $\mathrm{H} / \mathrm{N}$ & $\mathrm{A} / \mathrm{D} / \mathrm{E} / \mathrm{K} / \mathrm{N} / \mathrm{P} / \mathrm{T} N$ & LN & $\mathrm{E} / \mathrm{I} / \mathrm{K} / \mathrm{R} / \mathrm{T}$ & $\mathrm{A} / \mathrm{F} / \mathrm{H} / \mathrm{K} / \mathrm{P} / \mathrm{T} / \mathrm{Y}$ & A/D/E/G/N/P/Q/T \\
\hline Malaysian isolates & $\mathrm{D} / \mathrm{K} / \mathrm{N} / \mathrm{P} / \mathrm{R}$ & $\varnothing$ & $\varnothing$ & $\varnothing$ & E/N/Q/S/T & $\varnothing$ & $\varnothing$ & $\varnothing$ & $\mathrm{H} / \mathrm{N}$ & $\mathrm{A} / \mathrm{K} / \mathrm{T} N$ & $\mathrm{~L}$ & $\mathrm{E} / \mathrm{K} / \mathrm{T}$ & $\mathrm{F} / \mathrm{H} / \mathrm{P} / \mathrm{S} / \mathrm{Y}$ & $\mathrm{D} / \mathrm{E} / \mathrm{N} / \mathrm{R} / \mathrm{T}$ \\
\hline Loop & - & $\mathrm{BC}$ & $\mathrm{BC}$ & $\mathrm{BC}$ & $\mathrm{BC}$ & $\mathrm{BC}$ & $\mathrm{DE}$ & DE & - & - & - & - & - & - \\
\hline
\end{tabular}

\#Position is according to reference sequence, HRV-A (HRV-2, accession number: X02316); HRV-B (HRV-14, accession number: K02121).

${ }^{*}$ Position is according to reference sequence, HRV-C024 (accession number: EF582385).

${ }^{a}$ Denotes Nim-1A for HRV-A \& ${ }^{b}$ Denotes Nim-1A for HRV-B, otherwise denotes Nim-1B for HRV-A and -B.

(Ø), deletion. 
TABLE 3 | Comparison of potential deduced amino acids in the VP1 and carboxy-terminal VP3 regions involved in HRV-A and B major receptor binding with Malaysian isolates and other HRV-Cs.

\begin{tabular}{|c|c|c|c|c|c|c|c|c|c|}
\hline \multirow[t]{2}{*}{ HRV } & \multicolumn{5}{|c|}{ VP3 } & \multicolumn{4}{|c|}{ VP1 } \\
\hline & 179 & 180 & 181 & 182 & & 148 & 151 & & 213 \\
\hline \multirow[t]{2}{*}{ HRV-A major receptor } & $T^{\mathrm{a}}$ & $P$ & $D^{b}$ & \multicolumn{2}{|c|}{$\mathrm{A} / \mathrm{l} / \mathrm{K} / \mathrm{M} / \mathrm{N}^{\mathrm{b}} / \mathrm{S}^{\mathrm{b}} / \mathrm{T}$} & $\mathrm{G}^{\mathrm{b}}$ & 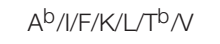 & \multicolumn{2}{|r|}{$\mathrm{A} / \mathrm{D}^{\mathrm{b}} / \mathrm{H}$} \\
\hline & 178 & 179 & 180 & \multicolumn{2}{|l|}{181} & 133 & 136 & \multicolumn{2}{|r|}{200} \\
\hline \multirow[t]{3}{*}{ Malaysian isolates ${ }^{\star}$} & $\mathrm{K} / \mathrm{R} / \mathrm{T}^{\mathrm{a}}$ & $\mathrm{A} / \mathrm{K} / \mathrm{S}$ & $\mathrm{D}^{\mathrm{b}}$ & \multicolumn{2}{|c|}{$\mathrm{D} / \mathrm{N}^{\mathrm{b}} / \mathrm{S}^{\mathrm{b}}$} & $G^{b}$ & $\mathrm{~A}^{\mathrm{b} / G / P / T^{\mathrm{b}}}$ & \multicolumn{2}{|r|}{$D^{b}$} \\
\hline & \multicolumn{9}{|c|}{ Amino acid position } \\
\hline & 177 & 178 & 179 & 180 & 226 & 155 & 159 & 206 & 217 \\
\hline Other HRV-Cs* & $K / R$ & $\mathrm{~A} / \mathrm{G} / \mathrm{K}^{\mathrm{b}} / \mathrm{R} / \mathrm{S}$ & $\mathrm{D}^{\mathrm{b}} / \mathrm{s}$ & $\mathrm{D} / \mathrm{E} / \mathrm{K} / \mathrm{N} / \mathrm{S}$ & $\mathrm{H} / \mathrm{P}$ & $\mathrm{Pb}^{\mathrm{b}}$ & $\mathrm{A} / \mathrm{G} / \mathrm{H} / \mathrm{P} / \mathrm{S} / \mathrm{T} / \mathrm{N}$ & $\mathrm{A} / \mathrm{I} / \mathrm{K} / \mathrm{L} / \mathrm{N} / \mathrm{R} / \mathrm{S} / \mathrm{T} / \mathrm{N}$ & $\mathrm{A} / \mathrm{E} / \mathrm{L} / \mathrm{P} / \mathrm{Q} / \mathrm{R} / \mathrm{S} / \mathrm{T} \mathrm{N}^{\mathrm{C}}$ \\
\hline Malaysian isolates ${ }^{\star}$ & $\mathrm{K} / \mathrm{R} / \mathrm{T}$ & $\mathrm{A} / \mathrm{K}^{\mathrm{b}} / \mathrm{S}$ & $D^{b}$ & D/N/S & $P$ & $\mathrm{P}^{\mathrm{b}}$ & $\mathrm{A} / \mathrm{G} / \mathrm{P} / \mathrm{T}$ & $\mathrm{A} / \mathrm{I} / \mathrm{T} N$ & $\mathrm{E} / \mathrm{L} / \mathrm{P} / \mathrm{Q} / \mathrm{S}$ \\
\hline
\end{tabular}

Major receptor binding positions of HRV-A and HRV-B were described by Kolatkar et al. (1999).

${ }^{\star}$ Position is according to reference sequence, HRV-C024 (accession number: EF582385).

${ }^{a}$ Additional deduced amino acid similarity is shown by Malaysian isolate (8713-MY-10).

b Similar deduced amino acids shared by HRV-A and B major receptor with Malaysian isolates and other HRV-Cs.

${ }^{c}$ Additional deduced amino acid displayed by other HRV-Cs but not in Malaysian isolates.

motifs were identified in the Malaysian isolates and other HRV-Cs.

Malaysian isolates are likely to carry a chymotrypsin-like cysteine $2 \mathrm{~A}$ protease with a catalytic triad, histidine $(\mathrm{H})$, aspartic acid (D), and cysteine (C) overlapped with the GDCG motif that facilitates initial cleavage at its capsid polyprotein. It also causes shutdown of the host cell protein synthesis (Hughes and Stanway, 2000). A zinc ligand, C-C-C-H, that helps to bind a zinc ion firmly for enzymatic activities was identified in the $2 \mathrm{~A}$ protein of the Malaysian isolates (Petersen et al., 1999). Two hydrophobic regions of the $2 \mathrm{~B}$ protein were identified in the Malaysian isolates. The first hydrophobic region is postulated to form a cationic amphipathic alpha helix, which is the major determinant for permeabilization of a host's plasma membrane (Agirre et al., 2002). Meanwhile, the second hydrophobic region may serve as a transmembrane domain to inhibit host protein secretion (van Kuppeveld et al., 1997). In addition, a NTPase motif, crucial for NTP binding and composed of the GXPGXGKS sequence (Gorbalenya et al., 1988), was found in the 2C protein of the Malaysian isolates. The DDLXQ motif is crucial for putative helicase function of 2C protein (de Souza Luna et al., 2008). This motif was found in one of the Malaysian isolates (8713MY-10/C23). The majority of the Malaysian isolates displayed the DDVXQ motif, while two of the Malaysian isolates (1570MY-10/C42 and 3805-MY-10/C12) showed DDIXQ motif. It is postulated that these three motifs (DDLXQ, DDVXQ and DDIXQ) play the same role as the amino acid properties of $\mathrm{L}, \mathrm{V}$, and I are similar. In addition, the Malaysian isolates $2 \mathrm{C}$ protein showed a cysteine-rich motif (CX2-4CX6-8CX3-4C) resembling a zinc finger, which is important in viral RNA replication
(Pfister et al., 2000). Overall, the features of the Malaysian isolates $2 \mathrm{~A}, 2 \mathrm{~B}$, and $2 \mathrm{C}$ proteins are similar to those of the other HRV-Cs.

Since there are no three-dimensional structures of HRV-C 3A protein, the characteristics of HRV-C $3 \mathrm{~A}$ protein were postulated based on another picornavirus, coxsackievirus. Hydrophobic packing and intermolecular salt bridges are important in coxsackievirus replication (Wessels et al., 2006). Malaysian isolates $3 \mathrm{~A}$ protein displayed I-L-L-S-V instead of I-L-L-V-V, suggesting the absence of hydrophobic packing. In addition, no intermolecular salt bridge was identified in the Malaysian isolates $3 \mathrm{~A}$ protein. Tyrosine, an important amino acid in the $3 \mathrm{~B}$ protein for linking covalently with viral RNA through a phosphodiester bond (Ambros and Baltimore, 1978), was conserved in the Malaysian isolates. Similar to the $2 \mathrm{~A}$ protein, $3 \mathrm{C}$ protein of Malaysian isolates was probably a chymotrypsin-like cysteine protease with slightly different catalytic triads, histidine $(\mathrm{H})$, glutamic acid (E), and cysteine (C) overlapped with GQCG motif (Matthews et al., 1994). Additionally, a substrate binding pocket, GXH (Matthews et al., 1994), was found in the 3C protein of four of the Malaysian isolates (1515-MY-10/C6, 3430-MY10/C22, 7383-MY-10/pat16, and 8097-MY-11/C26). Moreover, the Malaysian isolates 3C protein showed a conserved RNA binding motif, KFRDI (Shih et al., 2004). For the 3D protein, four conserved motifs; KDELR, GMPSG, YGDD, and FLKR (Appleby et al., 2005) were identified in Malaysian isolates. The KDELR motif constitutes part of a loop that joins the finger and thumb domain, which forms the active site of the 3D polymerase (Appleby et al., 2005). The YGDD motif is crucial for nucleotidyl transfer reaction (Beese and Steitz, 1991). Overall, 


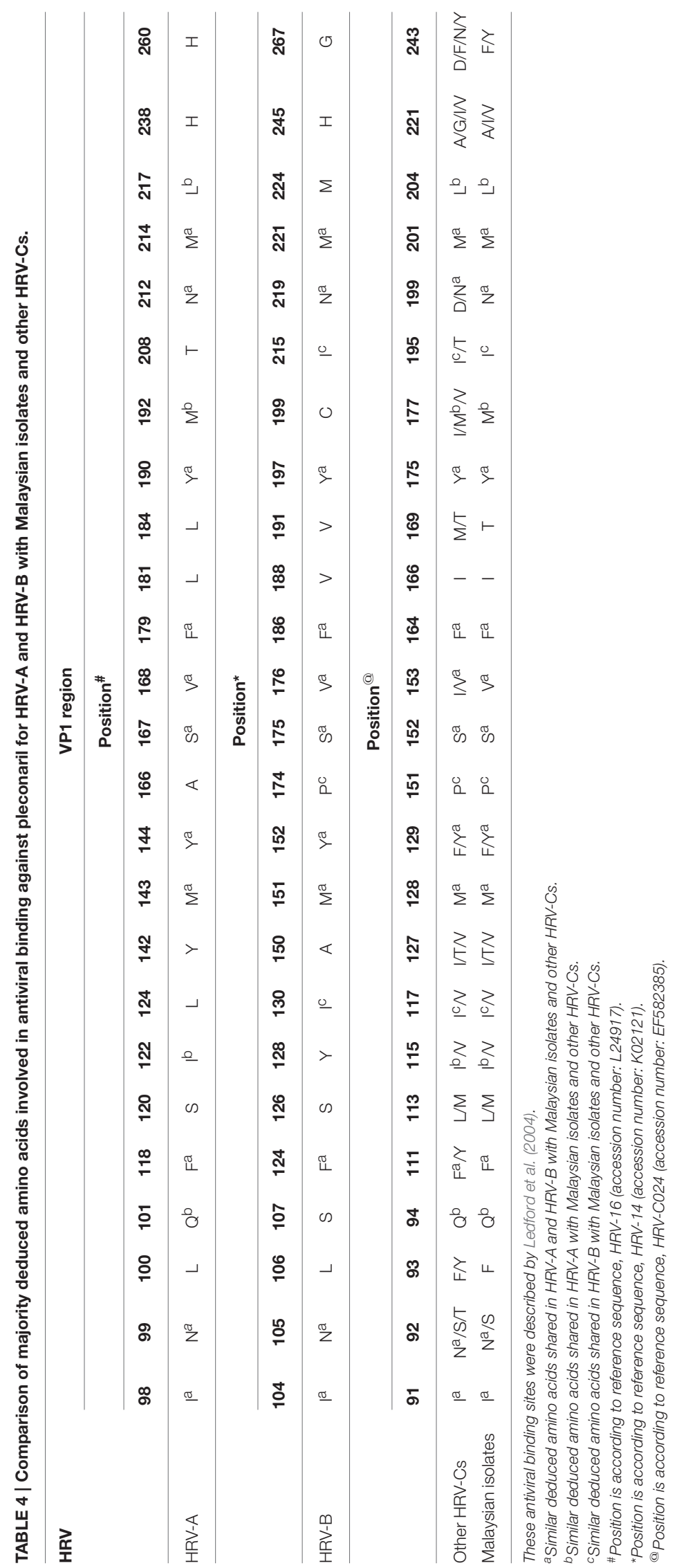


TABLE 5 | Summary of the genomic features of Malaysian isolates and other HRV-Cs.

\begin{tabular}{|c|c|c|c|}
\hline \multirow[t]{2}{*}{ Region } & \multirow[t]{2}{*}{ Conserved motif; Features } & \multicolumn{2}{|c|}{ Characteristics } \\
\hline & & Malaysian isolates & Other HRV-Cs \\
\hline \multirow[t]{2}{*}{ VP4 } & Myristylation site: GAQVS & Yes & Yes \\
\hline & Translation site: MGAQVS & Yes & Yes \\
\hline \multirow[t]{2}{*}{$2 \mathrm{~A}$} & Chymotrypsin-like protease with catalytic triad: H-D-C and GXCG motif & Yes & Yes \\
\hline & Zinc ligand: $\mathrm{C}-\mathrm{C}-\mathrm{C}-\mathrm{H}$ & Yes & Yes except N10/C9 \\
\hline 2B & Two hydrophobic regions & Yes & Yes \\
\hline \multirow[t]{3}{*}{$2 \mathrm{C}$} & NTPase motif: GXXGXGKS & Yes & Yes \\
\hline & Helicase: DDLXQ & One of the seven Malaysian isolates & Seven of 18 other HRV-Cs \\
\hline & Cysteine rich motif (CX2-4CX6-8CX3-4C) & Yes & Yes \\
\hline \multirow[t]{2}{*}{$3 \mathrm{~A}$} & Hydrophobic packing I-L-L-V-V & No & No \\
\hline & Intermolecular salt bridge D-K-K & No & No \\
\hline 3B & Phosphodiester bond: $Y_{3}$ & Yes & Yes \\
\hline \multirow[t]{3}{*}{$3 \mathrm{C}$} & Chymotrypsin-like protease with catalytic triad: H-E-C and GQCG motif & Yes & Yes \\
\hline & Substrate binding pocket: GXH & Four of the seven Malaysian isolates & Nine of 18 other HRV-Cs \\
\hline & RNA binding motif: KFRDI & Yes & Yes \\
\hline \multirow[t]{4}{*}{$3 \mathrm{D}$} & KDELR motif & Yes & Yes \\
\hline & GMPSG motif & Yes & Yes \\
\hline & YGDD motif & Yes & Yes \\
\hline & FLKR motif & Yes & Yes except JAL-1/C51 \\
\hline \multirow[t]{2}{*}{$5^{\prime} \mathrm{NCR}$} & Initial sequence, UU(A/G)AA(A/G)C(U/A)G & Yes & Yes \\
\hline & Two pyrimidine rich segments & Yes & Yes \\
\hline $3^{\prime} \mathrm{NCR}$ & Domain $Y$ & Yes & Yes \\
\hline
\end{tabular}

the characteristics of the Malaysian isolates 3A, 3B, 3C, and 3D proteins are similar to those of the other HRV-Cs.

A nine bp relatively conserved nucleotides sequence, $\mathrm{UU}(\mathrm{A} / \mathrm{G}) \mathrm{AA}(\mathrm{A} / \mathrm{G}) \mathrm{C}(\mathrm{U} / \mathrm{A}) \mathrm{G}$, was identified in the initial sequence of each Malaysian isolate $5^{\prime} \mathrm{NCR}$, where a VPg protein binds to the first $U$ of the sequence (Palmenberg et al., 2009) and initiates its translation. In addition, two pyrimidine-rich segments were observed in the Malaysian isolates. The first segment is postulated as a determinant of HRV-C pathogenecity as this segment is equivalent to neurovirulence tropism of poliovirus (Palmenberg et al., 2009); whereas, the second segment represents the HRV ribosome entry region which is important for translation initiation (Borman and Jackson, 1992). Malaysian isolates were found to share the same $5^{\prime}$ NCR characteristics with other HRV-Cs. Similar to other HRV-Cs, Malaysian isolates demonstrated domain Y in $3^{\prime}$ NCR (Pilipenko et al., 1992).

\section{HRV-C Complete Coding Sequences were Predominated by Purifying Selective Pressure}

A total of 2168 codon sites of the Malaysian isolates and other HRV-Cs aligned complete coding sequence were utilized for the selective pressure analysis. Negative selection was found to be the dominant selective pressure on HRV-C complete coding sequences using SLAC, FEL, and IFEL methods at $P<0.1$ level. These analyses (SLAC, FEL, and IFEL) found that $81 \%$ (1758/2168), 87\% (1886/2168), and 79\% (1716/2168) codon sites, respectively, were highly significant for purifying selections. The IFEL method demonstrated three positive selected sites but SLAC and FEL methods did not demonstrate any. These three positive selected sites were located in 852,943 , and 1030 codon position (Figure 3).

\section{DISCUSSION}

Respiratory infection is a significant burden in Malaysia (Khor et al., 2012). HRV infection, although usually associated with mild symptoms, can be associated with more severe acute respiratory infections and complications including asthma exacerbations (Lau et al., 2007). Due to the higher incidence of HRV-C in causing severe diseases and insufficient availability of HRV-C complete genome sequences for further analyses, the present study aimed to sequence the complete genome of Malaysian HRV-Cs and to perform genetic analyses of these viruses. These samples were previously confirmed as HRV-C based on the phylogenetic analysis of the VP4/VP2 region and designated as 1515-MY-10, 1570-MY-10, 3430-MY-10, 3805-MY10, 7383-MY-10, 8097-MY-11, and 8713-MY-10 (Chan et al., 2012). Seven HRV-C complete genome sequences consisting of $5^{\prime}$ and $3^{\prime}$ NCR, and the ORF were successfully amplified in this study. These seven Malaysian isolates were isolated from patients displaying a range of respiratory diseases such as bronchiolitis, staphylococcal pneumonia and acute exacerbations of bronchial asthma (AEBA). Low nucleotide similarity was observed in Malaysian isolates when compared to other HRV-Cs suggesting 


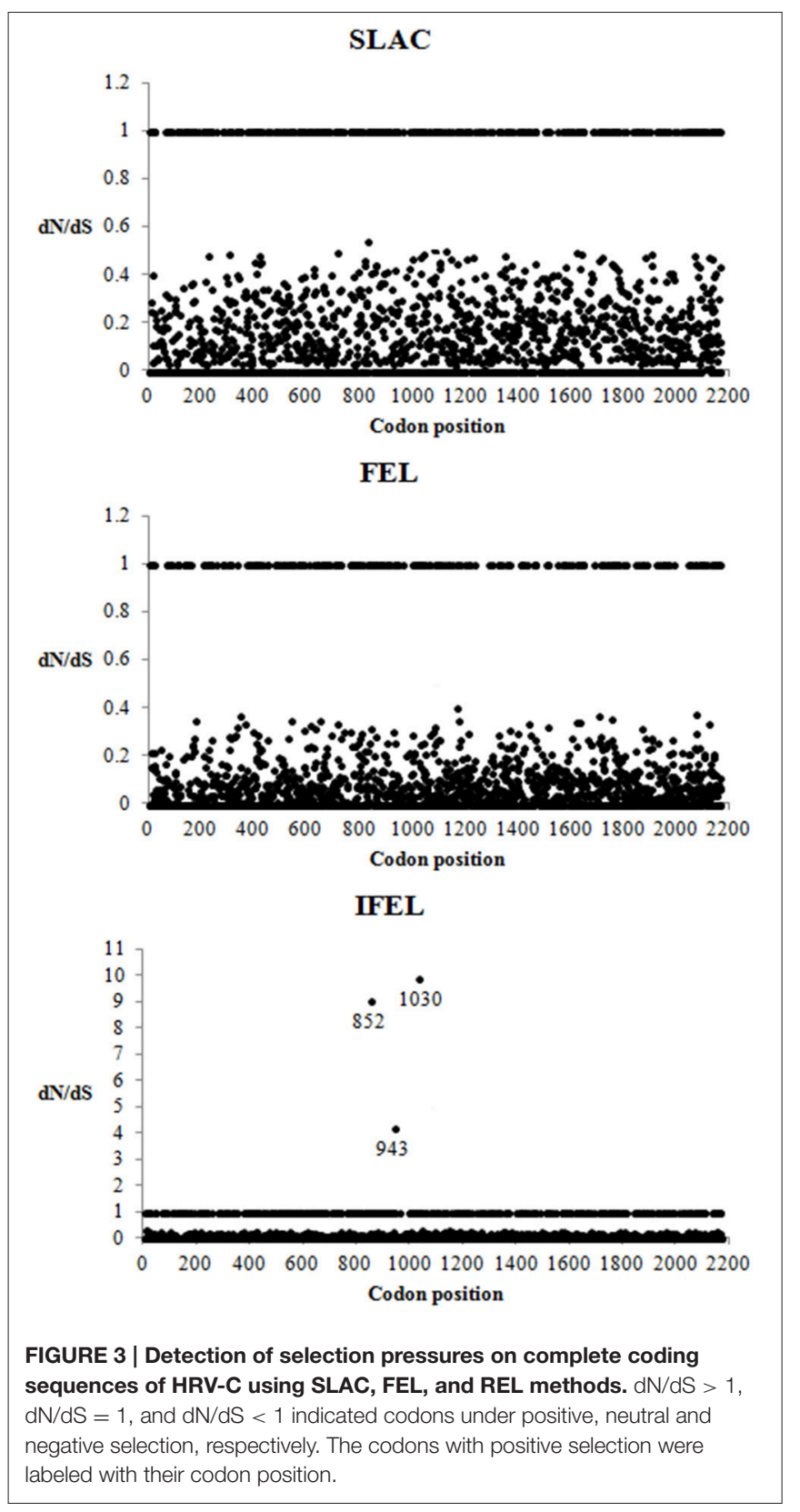

that these isolates are genetically diverse. Similar genetic diversity has been reported in HRV-C as well as HRV-A and HRV-B (Palmenberg et al., 2009). In addition, the previous primer sets from Lau et al. (2007) were unable to amplify all of the Malaysian isolates, further demonstrating the diverse nucleotide sequences of Malaysian isolates.

Groupings in phylogenetic analysis of HRV-C complete genome were different from previous VP4/VP2 phylogenetic analysis (Chan et al., 2012) which clustered 1515-MY-10, 3805MY-10, 3430-MY-10, 8713-MY-10, 8097-MY-11, 1570-MY-10, and 7383-MY-10 with HRV-C6, C12, C22, C23, C26, C42, and pat16, respectively. In the present study, phylogenetic analysis of VP1 gene demonstrated a similar clustering pattern with VP4/VP2 gene phylogenetic analysis, except for 7383-MY-10.
7383-MY-10 was clustered with C1 in the VP1 phylogenetic tree, and the similarity was only $83 \%$. The similarity is inconsistent with the classification proposed by Simmonds et al. (2010) suggesting a paucity of representative VP1 sequences for pat16. On the other hand, several short VP1 and VP4/VP2 sequences of C22, C23, C26, and C42 are available in Genbank. These sequences showed at least $87 \%$ similarity with their respective Malaysian isolate sequences (1570-MY-10, 3430-MY-10, $8097-$ MY-11, and 8713-MY-10).

McErlean et al. (2007) determined that the length of HRV$\mathrm{C}$ is shorter than HRV-A and HRV-B, as a result of several deletions in the $\mathrm{BC}, \mathrm{DE}$, and $\mathrm{HI}$ loops of $\mathrm{VP} 1$ region. Malaysian isolates have the same genome length as other HRV-Cs. The BC and DE loops are vital in major neutralization sites, especially Nim-1A and Nim-1B sites (Lau et al., 2007). The deletions of the putative neutralization sites in HRV-C remove the exposed loops and prevent the contact with host antibody; thus, HRV$\mathrm{C}$ may have the possibility to escape host antibody recognition. This could be the reason why HRV-C is responsible for more severe respiratory diseases as compared to other HRVs (Basta et al., 2014b). Besides that, more deletions in HRV-C of HRV-B immunogenic sites were observed as compared with HRV-A sites, suggesting that a vaccine or antiviral targeting the neutralization sites for HRV-C could be designed based on HRV-A instead of HRV-B.

As for host receptor binding, Lau et al. (2007) reported that HRV-Cs shared five out of the seven and four out of the nine conserved residues with major receptors of HRV-A and HRVB, respectively, based on a study by Kolatkar et al. (1999). The authors speculated that these HRV-Cs may not exploit the major receptor for host binding. One of the Malaysian isolates, 8713MY-10/C23, showed that its putative major receptor binding sites were very similar to HRV-A major receptor binding sites, as compared to other HRV-Cs. We speculate that this Malaysian isolate may not utilize the HRV-A major receptor because the binding sites required three fully conserved amino acids $\left(\mathrm{Thr}_{179}\right.$, $\mathrm{Pro}_{180}$, and $\mathrm{Asp}_{181}$ ) in the VP3 region (Laine et al., 2006), and this was not conserved in this isolate. Lack of amino acid similarity between Malaysian isolates and HRV-B major receptor binding site also suggests that the Malaysian isolates may not exploit this receptor either. In addition, the deletion of the HI loop of VP1 gene in the Malaysian isolates has removed the Lys 224 amino acid, which is crucial for minor receptor binding (Lau et al., 2007). Bochkov et al. (2011) demonstrated that HRV-C was still able to attach to the target cells although ICAM-1 (major receptor) and LDLR (minor receptor) antibodies were used to block these receptors. Taken together, these observations may imply that major and minor receptors are not utilized by HRV-C for attachment. Overall, the Malaysian isolates, like other HRVCs, are unlikely to utilize both the major and minor receptors for host binding based on genome sequence analysis. Recently, cadherin-related family member 3, a transmembrane protein with unknown function, was discovered as a possible receptor for HRV-C (Bochkov et al., 2015).

Arden et al. (2010) demonstrated 11 and 12 residue differences of HRV-C (HRVC-QCE) compared with HRV-A and HRV-B, respectively, among the 25 important contact residues of the 
antiviral binding pocket. With the increasing number of HRV-Cs, the Malaysian isolates and other HRV-Cs demonstrated a higher number of similar residues with HRV-A and HRV-B with respect to the antiviral binding pocket. Basta et al. (2014a) showed that four unique antiviral residues, $\mathrm{Phe} / \mathrm{Tyr}_{96}, \mathrm{Leu} / \mathrm{Met}_{116}, \mathrm{Ile} / \mathrm{Val}_{130}$, and $\mathrm{Ile}_{169}$ were only found in HRV-C, but not HRV-A and HRV-B. These residues were seen in the Malaysian isolates and are equivalent to $\mathrm{Phe} / \mathrm{Tyr}_{93}, \mathrm{Leu} / \mathrm{Met}_{113}$, Ile/Thr/Val 127 , and $\mathrm{Ile}_{166}$, respectively, in this study. Phe 96 and Met $_{116}$ of C15 have been shown to cause occasional steric clashes with some antiviral drugs (Basta et al., 2014a). According to the antiviral susceptibility pattern constructed by Basta et al. (2014a), Malaysian isolates and other HRV-Cs showed an additional unique residue, $\mathrm{Ala} / \mathrm{Gly} / \mathrm{Ile} / \mathrm{Val}_{221}$ in their sequences compared with HRV-A and HRV-B. These different residues of HRV-C undoubtedly changed the characteristic of HRV-C VP1 protein structure for antiviral binding, as compared to HRV-A and HRVB. In an antiviral study, Ledford et al. (2004) demonstrated that apparent resistance to pleconaril was developed from HRV$B$ with $P_{152}$ and $L_{1} u_{191}$ amino acids in the VP1 region. In the following year, Ledford et al. (2005) concluded that the resistance effect was most profound if both $\mathrm{Phe}_{152}$ and $\mathrm{Leu}_{191}$ were present concurrently in HRV. In the present study, none of the Malaysian isolates and other HRV-Cs demonstrated the simultaneous presence of these two amino acids. Recently, Hao et al. (2012) showed that HRV-C15 with only $\mathrm{Phe}_{129}$ amino acid (same as HRV-B Phe 152 amino acid) alone was capable of confering noticeable resistance to pleconaril. Most of the Malaysian isolates and other HRV-Cs demonstrated the presence of Phe $_{129}$ amino acid in the VP1 sequence, suggesting that they are likely resistant to pleconaril.

Negative selection was the dominant selective pressure acting on the HRV-C complete coding sequences. This result is in agreement with Kistler et al. (2007), which reported that most of the HRV coding regions were under strong negative selective pressure. Besides that, most of the motifs in the complete coding sequences displayed low ratio of the number of nonsynonymous substitutions per non-synonymous site to the number of synonymous substitutions per synonymous site. This indicates that these motifs have been under functional constraint throughout evolution. No positive selected sites were identified in HRV-C capsid region (Kuroda et al., 2015), whereas a positive selected site was reported in VP1 region of all HRVs complete coding sequences (86 HRV-A, 33 HRV-B, and 14 HRV-C) (Waman et al., 2014). A larger HRV-C dataset $(n=25)$ was exploited in the present study and several positive selective sites were identified using the IFEL method. One of these positive selected sites (852 codon position) was located in C-terminus of VP1 region, and it correlates with Waman et al. (2014). Another two positive selective pressures were found in $2 \mathrm{~A}$ and $2 \mathrm{~B}$ gene, respectively. The biological relevance of these three positive selected sites is hypothesized to increase in the HRV-C survival rate. For example, the positive selective site in C-terminus VP1 region is located on the outer surface, corresponding to the HRV-A antigenic site (269 position in HRV-C VP1 gene), and possibly interacts with host immune system (Table 2) resulting in the alteration of HRV-C immunogenicity. However, this hypothesis will require further support and verification from experimental data. For instance, the positively selected site is mapped within the Nim sites of HRV-A, it remains obscure whether this positive selective pressure affects the immunogenicity of $\mathrm{HRV}-\mathrm{C}$ as the immunogenic determinants of HRV-C have not been identified. To our knowledge, no studies focusing on these selected sites in HRV-C have been reported. Future studies are necessary to determine the biological importance of these positive selected sites. In turn, these findings can identify the pathogenic role of HRV-C in causing severe diseases.

\section{CONCLUSION}

Complete genomes of seven HRV-C Malaysian isolates have been sequenced and were classified as C6, C12, C22, C23, C26, C42, and pat 16 based on the pairwise distance threshold classification. This is the first report of complete genomes of C22, C23, C26, $\mathrm{C} 42$, and pat16. This study found that the putative biological characteristics of the Malaysian isolates were similar to those of other HRV-Cs. Moreover, negative selective pressure was the predominant pressure acting on complete coding sequences of HRV-C, and this pressure conserved the functional motif of these HRV-Cs, although the nucleotides were diverse. These indicate that a similar treatment and control of HRV-C can be applied to patients infected with these wide ranges of HRV-Cs. This study has represented the most up-to-date information about HRV-C genomics and shown that although HRV-Cs have diverse genetic sequences, they share conserved genomic features. Further in vitro and in vivo study will be required to clarify the HRV-C antiviral resistance and receptor binding sites that were predicted based on the genome sequences.

\section{AUTHOR CONTRIBUTIONS}

HYC, YFC, and NO participated in design of the study. YSK and FLJ performed the experiments. YSK, HYC, and YFC analyzed the data and drafted the manuscript. All authors revised and approved the final manuscript.

\section{ACKNOWLEDGMENTS}

We thank Cassi Henderson for checking the English. This study was supported by Research University Grant Scheme (RUGS grant 9370300), Universiti Putra Malaysia and Exploratory Research Grant Scheme (ERGS grant 5527164) from Ministry of Education, Malaysia awarded to HYC and High Impact Research Grant E000013-20001, University Malaya awarded to YFC. The funders had no role in study design, data collection and analysis, decision to publish or preparation of manuscript.

\section{SUPPLEMENTARY MATERIAL}

The Supplementary Material for this article can be found online at: http://journal.frontiersin.org/article/10.3389/fmicb. 2016.00543 


\section{REFERENCES}

Agirre, A., Barco, A., Carrasco, L., and Nieva, J. L. (2002). Viroporin-mediated membrane permeabilization. Pore formation by nonstructural poliovirus $2 \mathrm{~B}$ protein. J. Biol. Chem. 277, 40434-40441. doi: 10.1074/jbc.M205393200

Ambros, V., and Baltimore, D. (1978). Protein is linked to the $5^{\prime}$ end of poliovirus RNA by a phosphodiester linkage to tyrosine. J. Biol. Chem. 253, 5263-5266.

Appleby, T. C., Luecke, H., Shim, J. H., Wu, J. Z., Cheney, W. I., Zhong, W. D., et al. (2005). Crystal structure of complete rhinovirus RNA polymerase suggests front loading of protein primer. J. Virol. 79, 277-288. doi: 10.1128/JVI.79.1.277288.2005

Appleyard, G., Russell, S. M., Clarke, B. E., Speller, S. A., Trowbridge, M., and Vadolas, J. (1990). Neutralization epitopes of human rhinovirus type 2. J. Gen. Virol. 71, 1275-1282. doi: 10.1099/0022-1317-71-6-1275

Arden, K. E., Faux, C. E., O’Neill, N. T., McErlean, P., Nitsche, A., Lambert, S. B., et al. (2010). Molecular characterization and distinguishing features of a novel human rhinovirus (HRV) C, HRVC-QCE, detected in children with fever, cough and wheeze during 2003. J. Clin. Virol. 47, 219-233. doi: 10.1016/j.jcv.2010.01.001

Basta, H. A., Ashraf, S., Sgro, J. Y., Bochkov, Y. A., Gern, J. E., and Palmenberg, A. C. (2014a). Modeling of the human rhinovirus C capsid suggests possible causes for antiviral drug resistance. Virology 448, 82-90. doi: 10.1016/j.virol.2013.10.004

Basta, H. A., Sgro, J. Y., and Palmenberg, A. C. (2014b). Modeling of the human rhinovirus C capsid suggests a novel topography with insights on receptor preference and immunogenicity. Virology 448, 176-184. doi: 10.1016/j.virol.2013.10.006

Beese, L. S., and Steitz, T. A. (1991). Structural basis for the 3'-5'exonuclease activity of Escherichia coli DNA polymerase I: a two metal ion mechanism. ЕМВО J. 10, 25-33.

Bochkov, Y. A., Palmenberg, A. C., Lee, W. M., Rathe, J. A., Amineva, S. P., Sun, X., et al. (2011). Molecular modeling, organ culture and reverse genetics for a newly identified human rhinovirus C. Nat. Med. 17, 627-633. doi: 10.1038/nm. 2358

Bochkov, Y. A., Watters, K., Ashraf, S., Griggs, T. F., Devries, M. K., Jackson, D. J., et al. (2015). Cadherin-related family member 3, a childhood asthma susceptibility gene product, mediates rhinovirus $\mathrm{C}$ binding and replication. Proc. Natl. Acad. Sci. U.S.A. 112, 5485-5490. doi: 10.1073/pnas.1421178112

Borman, A., and Jackson, R. J. (1992). Initiation of translation of human rhinovirus RNA: mapping the internal ribosome entry site. Virology 188, 685-696. doi: 10.1016/0042-6822(92)90523-R

Chan, Y. F., Jafar, F. L., Nathan, A. M., de Bruyne, J. A., Hassan, A., Nor'e, S. S., et al. (2012). Diverse human rhinoviruses A and C from children with respiratory infections in Kuala Lumpur, Malaysia. J. Infection 64, 633-636. doi: 10.1016/j.jinf.2012.03.011

Darriba, D., Taboada, G. L., Doallo, R., and Posada, D. (2012). jModelTest 2: more models, new heuristics and parallel computing. Nat. Methods 9:772. doi: 10.1038/nmeth.2109

de Souza Luna, L. K., Baumgarte, S., Grywna, K., Panning, M., Drexler, J. F., and Drosten, C. (2008). Identification of a contemporary human parechovirus type 1 by VIDISCA and characterization of its full genome. Virol. J. 5:26. doi: $10.1186 / 1743-422 \mathrm{X}-5-26$

Etemadi, M. R., Othman, N., Savolainen-Kopra, C., Sekawi, Z., Wahab, N., and Sann, L. M. (2013). Biodiversity and clinico-demographic characteristics of human rhinoviruses from hospitalized children with acute lower respiratory tract infections in Malaysia. J. Clin. Virol. 58, 671-677. doi: 10.1016/j.jcv.2013.05.017

Gorbalenya, A. E., Koonin, E. V., Donchenko, A. P., and Blinov, V. M. (1988). A conserved NTP-motif in putative helicases. Nature 333:22. doi: $10.1038 / 333022 \mathrm{a} 0$

Hall, T. A. (1999). BioEdit, a user-friendly biological sequence alignment editor and analysis program Windows 95/98/NT. Nucleic Acid Symp. Ser. 41, 95-98. doi: 10.1021/bk-1999-0734.ch008

Hao, W., Bernard, K., Patel, N., Ulbrandt, N., Feng, H., Svabek, C., et al. (2012). Infection and propagation of human rhinovirus $\mathrm{C}$ in human airway epithelial cells. J. Virol. 86, 13524-13532. doi: 10.1128/JVI.02094-12

Hughes, P. J., and Stanway, G. (2000). The 2A proteins of three diverse picornaviruses are related to each other and to the H-rev107 family of proteins involved in the control of cell proliferation. J. Gen. Virol. 81, 201-207. doi: 10.1099/0022-1317-81-1-201

Khor, C. S., Sam, I. C., Hooi, P. S., Quek, K. F., and Chan, Y. F. (2012). Epidemiology and seasonality of respiratory viral infections in hospitalized children in Kuala Lumpur, Malaysia: a retrospective study of 27 years. BMC Pediatr. 12:32. doi: 10.1186/1471-2431-12-32

Kistler, A. L., Webster, D. R., Rouskin, S., Magrini, V., Credle, J. J., Schnurr, D. P., et al. (2007). Genome-wide diversity and selective pressure in the human rhinovirus. Virol. J. 4:40. doi: 10.1186/1743-422X-4-40

Kolatkar, P. R., Bella, J., Olson, N. H., Bator, C. M., Baker, T. S., and Rossmann, M. G. (1999). Structural studies of two rhinovirus serotypes complexed with fragments of their cellular receptor. $Е M B O ~ J .18,6249-6259$. doi: 10.1093/emboj/18.22.6249

Kuroda, M., Niwa, S., Sekizuka, T., Tsukagoshi, H., Yokoyama, M., Ryo, A., et al. (2015). Molecular evolution of the VP1, VP2, VP3 genes in human rhinovirus species C. Sci. Rep. 5:8185. doi: 10.1038/srep08185

Laine, P., Blomqvist, S., Savolainen, C., Andries, K., and Hovi, T. (2006). Alignment of capsid protein VP1 sequences of all human rhinovirus prototype strains, conserved motifs and functional domains. J. Gen. Virol. 87, 129-138. doi: 10.1099/vir.0.81137-0

Lamson, D., Renwick, N., Kapoor, V., Liu, Z., Palacios, G., Ju, J., et al. (2006). MassTag polymerase-chain-reaction detection of respiratory pathogens, including a new rhinovirus genotype, that caused influenza-like illness in New York State during 2004-2005. J. Infect. Dis. 194, 1398-1402. doi: $10.1086 / 508551$

Lau, S. K., Yip, C. C., Tsoi, H. W., Lee, R. A., So, L. Y., Lau, Y. L., et al. (2007). Clinical features and complete genome characterization of a distinct human rhinovirus (HRV) genetic cluster, probably representing a previously undetected HRV species, HRV-C, associated with acute respiratory illness in children. J. Clin. Virol. 45, 3655-3664. doi: 10.1128/JCM.01254-07

Ledford, R. M., Collett, M. S., and Pevear, D. C. (2005). Insights into the genetic basis for natural phenotypic resistance of human rhinoviruses to pleconaril. Antiviral Res. 68, 135-138. doi: 10.1016/j.antiviral.2005.08.003

Ledford, R. M., Patel, N. R., Demenczuk, T. M., Watanyar, A., Herbertz, T., Collett, M. S., et al. (2004). VP1 sequencing of all human rhinovirus serotypes: insights into genus phylogeny and susceptibility to antiviral capsidbinding compounds. J. Virol. 78, 3663-3674. doi: 10.1128/JVI.78.7.36633674.2004

Matthews, D. A., Smith, W. W., Ferre, R. A., Condon, B., Budahazi, G., Slsson, W., et al. (1994). Structure of human rhinovirus 3C protease reveals a trypsin-like polypeptide fold, RNA-binding site, and means for cleaving precursor polyprotein. Cell 77, 761-771. doi: 10.1016/0092-8674(94) 90059-0

McErlean, P., Shackelton, L. A., Lambert, S. B., Nissen, M. D., Sloots, T. P., and Mackay, I. M. (2007). Characterisation of a newly identified human rhinovirus, HRV-QPM, discovered in infants with bronchiolitis. J. Clin. Virol. 39, 67-75. doi: 10.1016/j.jcv.2007.03.012

McIntyre, C. L., Knowles, N. J., and Simmonds, P. (2013). Proposals for the classification of human rhinovirus species A, B and C into genotypically assigned types. J. Gen. Virol. 94, 1791-1806. doi: 10.1099/vir.0.053686-0

Miller, E. K., Khuri-Bulos, N., Williams, J. V., Shehabi, A. A., Faouri, S., Al Jundi, I., et al. (2009). Human rhinovirus C associated with wheezing in hospitalised children in the Middle East. J. Clin. Virol. 46, 85-89. doi: 10.1016/j.jcv.2009.06.007

Nicholas, K. B., Nicholas, H. B. J., and Deerfield, D. W. (1997). GeneDoc: analysis and visualization of genetic variation, EMBNEW. NEWS 4, 14.

Palmenberg, A. C., Rathe, J. A., and Liggett, S. B. (2010). Analysis of the complete genome sequences of human rhinovirus. J. Allergy Clin. Immunol. 125, 1190-1199. doi: 10.1016/j.jaci.2010.04.010

Palmenberg, A. C., Spiro, D., Kuzmickas, R., Wang, S., Djikeng, A., Rathe, J. A., et al. (2009). Sequencing and analyses of all known Human Rhinovirus genomes reveal structure and evolution. Science 324, 55-59. doi: 10.1126/science. 1165557

Paul, A. V., Schultz, A., Pincus, S. E., Oroszlan, S., and Wimmer, E. (1987). Capsid protein VP4 of poliovirus is N-myristoylated. Proc. Natl. Acad. Sci. U.S.A. 84, 7827-7831.

Petersen, J. F. W., Cherney, M. M., Liebig, H. D., Skern, T., Kuechler, E., and James, M. N. G. (1999). The structure of the 2 A proteinase from a common cold virus, 
a proteinase responsible for the shut-off of host-cell protein synthesis. EMBO J. 18, 5463-5475. doi: 10.1093/emboj/18.20.5463

Pfister, T., Jones, K. W., and Wimmer, E. (2000). A Cysteine-Rich motif in poliovirus protein 2C ATPASE is involved in RNA replication and binds zinc in vitro. J. Virol. 74, 334-343. doi: 10.1128/JVI.74.1.334-343.2000

Picornaviridae Study Group (2014). Rhinovirus C. Available online at: http://www.picornastudygroup.com/types/enterovirus/hrv-c.htm.

Pilipenko, E. V., Maslova, S. V., Sinyakov, A. N., and Agol, V. I. (1992). Towards identification of cis-acting elements involved in the replication of enterovirus and rhinovirus RNAs: a proposal for the existence of tRNAlike terminal structures. Nucleic Acids Res. 20:1739. doi: 10.1093/nar/20. 7.1739

Pond, S. L., and Frost, S. D. (2005). Datamonkey, rapid detection of selective pressure on individual sites of codon alignments. Bioinformatics 21, 2531-2533. doi: 10.1093/bioinformatics/bti320

Rossmann, M. G., Arnold, E., Erickson, J. W., Frankenberger, E. A., Griffith, J. P., Hecht, H. J., et al. (1985). Structure of a human common cold virus and functional relationship to other picornaviruses. Nature 317, 145-153. doi: $10.1038 / 317145 \mathrm{a} 0$

Shih, S. R., Chiang, C., Chen, T. C., Wu, C. N., Hsu, J. T., Lee, J. C., et al. (2004). Mutations at KFRDI and VGK domains of enterovirus $713 \mathrm{C}$ protease affects its RNA binding and proteolytic activities. J. Biomed. Sci. 11, 239-248. doi: 10.1007/BF02256567

Simmonds, P., McIntyre, C., Savolainen-Kopra, C., Tapparel, C., Mackay, I. M., and Hovi, T. (2010). Proposals for the classification of human rhinovirus species C into genotypically assigned types. J. Gen. Virol. 91, 2409-2419. doi: 10.1099/vir.0.023994-0
Tamura, K., Stecher, G., Peterson, D., Filipski, A., and Kumar, S. (2013). MEGA6, molecular evolutionary genetics analysis version 6.0. Mol. Biol. Evol. 30, 2725-2729. doi: 10.1093/molbev/mst197

van Kuppeveld, F. J. M., Hoenderop, J. G. J., Smeets, R. L. L., Willems, P. H. G. M., Dijkman, H. B. P. M., Galama, J. M. D., et al. (1997). Coxsackievirus protein $2 \mathrm{~B}$ modifies endoplasmic reticulum membrane and plasma membrane permeability and facilitates virus release. $E M B O ~ J .16,3519-3532$. doi: 10.1093/emboj/16.12.3519

Waman, V. P., Kolekar, P. S., Kale, M. M., and Kulkarni-Kale, U. (2014). Population structure and evolution of rhinovirus. PLOS ONE 9:e88981. doi: 10.1371/journal.pone.0088981

Wessels, E., Notebaart, R. A., Duijsings, D., Lanke, K., Vergeer, B., Melchers, W. J. G., et al. (2006). Structure-function analysis of the coxsackievirus protein $3 \mathrm{~A}$ identification of residues important for dimerization, viral RNA replication and transport inhibition. J. Biol. Chem. 281, 28232-28243. doi: 10.1074/jbc.M601122200

Conflict of Interest Statement: The authors declare that the research was conducted in the absence of any commercial or financial relationships that could be construed as a potential conflict of interest.

Copyright (๑) 2016 Khaw, Chan, Jafar, Othman and Chee. This is an open-access article distributed under the terms of the Creative Commons Attribution License (CC $B Y)$. The use, distribution or reproduction in other forums is permitted, provided the original author(s) or licensor are credited and that the original publication in this journal is cited, in accordance with accepted academic practice. No use, distribution or reproduction is permitted which does not comply with these terms. 